\title{
MIGRAÇÃO, VIOLÊNCIA E RETORÇÃO
}

\author{
MIGRATION, VIOLENCE AND RETORTION
}

\section{Carlos Emilio Ibarra Montero ${ }^{1}$ \\ Francisco Ramos de Farias ${ }^{2}$}

\section{Resumo}

Este artigo é um exercício que pretende incentivar a reflexão sobre a migração a partir de uma perspectiva transdisciplinar que questiona as interações que se desenvolvem entre o cientista e o migrante. Partimos da ideia de que o migrante é violentado de duas maneiras: a primeira, pelos diversos dispositivos de observação utilizados pelo pesquisador, e a segunda, pela simulação do cientista, que desconsidera a importância da retorção que os migrantes aparentemente apresentam. Estima-se que a retorção seja uma forma de reação à violência infligida aos migrantes pelo fato de serem o objeto de estudo de uma pesquisa. Mediante a releitura de trabalhos investigativos que versam sobre migração, a análise de documentos digitais como documentários e filmes e as experiências vividas nas pesquisas de campo desenvolvidas nos últimos seis anos, pretendemos abordar a pesquisa de forma crítica, com vistas a pensar os diferentes caminhos que as ciências humanas têm percorrido e seus impactos, com o intuito de encontrar o "real" ou, parafraseando Jean Baudrillard, de encontrar aquilo que é mais real do que o real.

Palavras-chave: Migração; Retorção; Violência.

\begin{abstract}
This article is an exercise that intends to encourage the reflection about migration through a transdisciplinarity perspective that questions the interactions developed between the scientist and the migrant. It starts from the idea that the migrant is violated in two ways: first, by the diferent observation devices used by the researcher, and the second, by the scientist simulation which disconsider the importance of the retortion that migrants apparently present. It is esteemed that retortion is a form of reaction to the violence inflicted to migrants by the fact that they are the object of a research study. one, by the simulation made by the scientist in not remarking the importance of the retort apparently presented by the migrants as a way of reacting to the violence that represents the fact that they are the object of study. Through rereading some studies about migration issues, analyzing digital documents such as documentaries and films and the experiences lived in the field research in the last six years, we take a critical approach to thinking about the different ways human sciences have taken, and

\footnotetext{
${ }^{1}$ Doutorando no Programa de Pós-Graduação em Memória Social da Universidade Federal do Estado do Rio de Janeiro (UNIRIO). Pesquisador sobre temas migratorios e professor em Ciências Políticas e Sociologia da Universidad Autónoma de Sinaloa, México (UAS). Bolsista do programa de qualidade do Concejo Nacional de Ciencia y Tecnología, México (CONACyT). E-mail: carlos.iba.bra@gmail.com

2 Doutor em Psicologia Clínica pela Fundação Getúlio Vargas. Coordenador e professor do Programa de Pós Graduação em Memória Social da Universidade Federal do Estado do Rio de Janeiro (UNIRIO). E-mail: frfarias@uol.com.br
} 
their impact, in order to find the "real" or, to paraphrase Jean Baudrillard, to find that which is more real than the real.

Keywords: migration; retortion; violence.

\section{INTRODUÇÃO}

O que nos faz supor que o migrante quer falar? Não será talvez que nós, em nossa postura "superior" de cientistas, os obrigamos a fazê-lo?

Começaremos com dois questionamentos que são também dois grandes blocos de concreto, pesados, densos e que fazem tanto ruído durante o processo de pensar a migração que não podem ser ignorados nem subestimados. Se fizéssemos uma revisão cronológica das ciências humanas, iríamos observar que os estudos desenvolvidos no contorno da cultura ocidental nas últimas décadas estiveram e estão focados na abordagem do fenômeno da migração em uma perspectiva "humanista", que pretende "dar voz" aos intérpretes e atores do fenômeno da migração. É o famoso "empoderamento" das "vítimas".

A fenomenologia ${ }^{3}$ (THOMAS \& ZNANIECKY, 1918; HUSSERL, 1984; MERLEAU-PONTY, 1993) e o interacionismo simbólico ${ }^{4}$ (BLUMER, 2013) são algumas das correntes de análise que têm um importante sucesso nos estudos sobre migrações, pois exploram o fenômeno a partir das histórias e experiências de vida, dos discursos dos migrantes, da observação participante, das entrevistas não estruturadas, das narrativas etc. Isso tem definido uma pauta no campo das migrações porque em vez de o migrante fazer parte da estatística, em vez de ser só um número, passa a ser "protagonista" ao serem transcritas suas falas, entrevistas, discursos. Todas essas informações - posteriores às edições subjetivas do cientista - são publicadas em artigos científicos, teses, ensaios, monografias etc. e são utilizadas como armas letais que justificam e afirmam hipóteses que depois viram conclusões ou incertezas.

\footnotetext{
${ }^{3}$ A fenomenologia pretende analisar a essência encontrada na relação entre a consciência e os objetos, sendo a construção da realidade feita por cada indivíduo a partir do uso dos sentidos e sua relação ou intencionalidade para com os objetos e os outros atores da sociedade.

${ }^{4}$ Segundo o interacionismo simbólico, os seres humanos interpretam ou definem as ações dos outros, em vez de simplesmente reagir a elas. O significado atribuído às ações é construído mediante símbolos, interpretações e a atribuição de significados dos outros - neste caso, os atores que fazem parte direta ou indiretamente do ambiente em que se dá a dinâmica social. Uma das características importantes do interacionismo simbólico é dar atenção quase exclusiva à compreensão da ação social a partir do ponto de vista do ator.
} 
É evidente que a mudança de postura das ciências humanas, que deixou de lado a certeza para instaurar a relativização, foi revolucionária. Mas essa revolução trouxe novas incógnitas para os interessados no estudo do fenômeno das migrações. Inclusive, os dois questionamentos colocados no começo deste trabalho fazem parte desses novos desafios, que não procuram nem dar certeza nem incerteza, mas sim, realizar uma análise da migração, entendendo o migrante como um objeto que é violentado de duas maneiras. A primeira se dá pelo uso dos diversos dispositivos de observação que não permitem ao migrante responder ou reagir. A segunda, pelo silêncio do observador diante da importância da retorção ativa que os migrantes apresentam, por serem questionados e violados.

A partir da reflexão anterior, podemos então começar a pensar que, talvez, a retorção dos migrantes pode ser o equiparável a uma vingança que se dá por meio de respostas, falas e histórias de vida que versem sobre o que a nossa área das ciências humanas quer ouvir e não sobre aquilo que é efetivamente pensado ou vivido por eles.

Os novos desafios ou questionamentos que neste trabalho são colocados não pretendem encontrar respostas e sim dinâmicas de pensamento que permitam dialogar com diversas áreas do conhecimento. Pretendemos, assim, gerar novas discussões e, ao mesmo tempo, aprimorar nossos questionamentos inicias.

\section{A VIOLÊNCIA COMO FERRAMENTA DA CIÊNCIA}

Atualmente, uma das posturas do pesquisador é sortear e usar os contornos imprecisos e complexos do entendimento sobre as organizações sociais ou, então, sobre as unidades de ação das quais faz parte o ser humano, para dizer que não houve pretensão de se responder às perguntas expostas no estudo. Um grande ato de "humildade científica". No entanto, nós, pesquisadores, adotamos posturas definidas, recortadas, nos sujeitamos à ciência e estabelecemos cronogramas de atividades baseados em prognósticos de tempo e de orçamento (metodologia), todo um artificio para o desenvolvimento da pesquisa com a qual pretendemos dar ordem ao mundo, um mundo em que a única coisa que existe é a incerteza. Mas mesmo sabendo isso, como sujeitos da ciência, tentamos prender o objeto mediante esse exercício de violência e de ilusão perpétua, guiados pelo desejo de desvendar a "mentira" para encontrar a "verdade" ou o "real". No pior dos casos, nossa sujeição à ciência se dá com a finalidade de encontrar "pegadas" do objeto para mostrar que aquela verdade que se falou sobre ele é "superficial" e que existe uma verdade que é ainda "hiper-real". 
Quando a temática a ser abordada é sobre algum dos rostos mais escancarados da violência - como é o caso da migração - ou quando, inclusive, nosso objeto de estudo é o conceito de violência, nossos discursos e escritas científicas são convertidos em "ferramentas de justiça", que achamos serem invencíveis na hora de encarar os injustos. Nesses casos, é comum a ideia assim expressa: nosso compromisso é ético em todas as partes do processo de construção de conhecimento e nós compreendemos a dor de todos aqueles que sofreram os terríveis atos de violência, quer sejam estes do Estado, dos grupos terroristas ou do crime organizado, quer sejam das catástrofes naturais, da ciência e seus experimentos e efeitos etc. Assim, nossa pesquisa condena aqueles agentes que utilizam a violência como uma forma de alcançar seus objetivos de forma a saciar sua fome de prazer. De nosso patamar da ciência objetiva, não seremos solidários com os atores violentos mesmo quando estes sejam parte da condição humana, pois segundo Stengers (2002, p. 19) "como se pode aceitar que se enxergue nas ciências a expressão de uma racionalidade em livre curso, escapando ao controle dos homens, dedicada a negar, a submeter ou destruir tudo o que ela não pode reduzir ao calculável e a manipulável".

Tal discurso é uma constante nas pesquisas de todas as áreas da ciência, mas sem sombra de dúvida, são as ciências humanas as que mais explicitamente exploram e se posicionam em relação ao "compromisso ético", de forma a vingar a "injustiça" sofrida pelos despossuídos, marginalizados, excluídos, estigmatizados, violados, estuprados, assassinados etc.

É justamente nesse processo de nos acharmos éticos, inteligentes, objetivos, qualificados (e, em alguns casos, hiperqualificados), que cometemos atos de uma violência tão sutil que é difícil de ser enxergada até por nós mesmos. Daí vem o fato de não sabermos quais estragos poderíamos ter causado naquelas pessoas que foram presas de nosso desejo de saciar essa fome de curiosidade.

Se pretendêssemos justificar nossa atitude ou postura de cientistas por meio do conceito da violência positiva, numa lógica na qual os males existem para gerar o bem, teríamos que ter também instrumentos que permitissem medir aquilo que, sendo humano e social, não é mensurável. Porém, desejamos boa sorte àqueles que, numa crise de histeria referencial ${ }^{5}$ ou conceitual, tentem fazê-lo.

Se alguma coisa sabemos de nós mesmos é que somos animais movidos pela curiosidade de desvendar o desconhecido, de conhecer aquilo que está fora de nós, ou seja, a

\footnotetext{
${ }^{5}$ Jean Baudrillard utiliza este termo no seu trabalho intitulado As estratégias fatais (1996) para definir aquelas pessoas que pretendem dar sentido ao mundo mediante o uso do conhecimento analítico.
} 
nossa essência originária ou topus, que é construído pelo saber (FARIAS, 2014). E se a nossa existência vai estar delimitada pelo encontro do saber, que se estabelece precisamente nas unidades de ação, isto é, nas relações interpessoais, se isso efetivamente for assim, então estaremos condenados a ser violentos, não só aqueles que escolhem a profissão de cientistas, mas todos aqueles que são curiosos, ou seja, aqueles que são humanos.

Todos os bens culturais têm origem na barbárie e devem sua existência não só àqueles que os criaram, configuraram ou desenharam, mas também a todos aqueles contemporâneos que se submeteram a esses bens e, simultaneamente, usufruíram deles (BENJAMIN, 1940).

O monumento da barbárie não é em si uma coisa, um objeto, algo tangível. O monumento da barbárie é a dinâmica social que tem como intuito alcançar o "progresso". Com isso, não queremos dizer que o cientista e o ladrão são iguais, mas, sobretudo, pretendemos discutir o quanto os mecanismos e ferramentas cientificas utilizadas para procurar a razão por parte do cientista, podem representar formas de violência, que, sem sombra de dúvida, são diferentes. Nos dois parágrafos seguintes explicaremos no que consiste essa diferença.

Partimos da ideia de que, no mundo ocidental, nem a lei e nem o direito poderiam existir sem o exercício da violência. É, inclusive, uma tarefa titânica imaginar novos mecanismos que garantam um "Estado de direito" sem o uso da força bruta, até porque o próprio conceito de Estado de direito é historicamente uma configuração violenta. Mas quais são as diferenças entre a força bruta exercida pelo carrasco e a ação bárbara exercida pelo Estado? É a valorização do pactuado pela comunidade sobre aquilo que é desejado pelo indivíduo. É o prevalecimento da violência do coletivo sobre a violência individual (FREUD, 1932/1976).

Nos casos da violência exercida pelo cientista e da violência que pratica um ladrão, existem diferenças. Enquanto a primeira ação bruta faz parte de um acordo que a comunidade legitima por meio de um discurso que promete o "progresso"; a segunda prática, executada pelo delinquente, é produto do desejo individual, ou seja, ela não faz parte dessa proposta utópica ${ }^{6}$ procurada pela comunidade. Isso significa que que o delinquente não só deve como também tem que ser ou punido, ou exterminado, ou afastado, tudo para não obstaculizar o projeto da comunidade. "A lei é a força de uma comunidade" (FREUD, 1932/1976, p. 32).

\footnotetext{
${ }^{6} \mathrm{O}$ uso do conceito utopia no presente trabalho, pretende fazer referência ao pensamento de Michael Foucault no livro As palavras e as coisas: uma arqueologia das ciências humanas (1966). Utopia é aquele lugar, ação, objetivos coerentes, que não existem na realidade, mas que existem no imaginário do pacto do coletivo, quer dizer, a utopia é uma espécie de sonho que, se por acaso um dia virasse realidade, seria aceita e legitimada pela comunidade e por conseguinte pela lei.
} 
Poderíamos acrescentar que a ciência também é a força de uma comunidade e que ela pode entrar em ação a qualquer momento e contra qualquer pessoa.

Contudo, podemos dizer que o ato violento da procura é o elemento fundador da ciência. Foi a curiosidade que levou o homem a usar a força para transformar uma pedra num paralelepípedo, que depois se converteu em arma rupestre para a caça e a luta entre tribos, sendo utilizado, também, para construir muros, prisões, estradas. Foi essa mesma curiosidade que levou o homem a explorar o espaço a tal ponto de conseguir se transportar para lá: nossas pegadas, restos, rastros, fazem parte hoje do universo.

Aderido a esse "hiperdesenvolvimento", veio um dualismo sob tensão - interação violenta - entre a razão e a cultura, entre o mundo objetivo e o mundo subjetivo, entre os bárbaros e os civilizados. De um lado estão os atores e do outro lado está o sistema. De um lado, a explosão da ciência, da técnica e o consumo, enquanto do outro lado, a resistência cultural, as identidades (TOURAINE, 1992).

$O$ ato violento de sermos curiosos, de querermos encontrar e saber aquilo que está fora de nós é o que melhor define nosso presente, que se não é desenvolvido, evoluído ou progressista, tampouco é o oposto disso. Sobretudo, é algo humano. É importante também relembrar que, se existiu alguma época da ciência mais marcada pelo envilecimento do que pelo enobrecimento, essa foi a do mundo moderno que tem seguido a lógica do consumo e da hiperprodução (BAUDRILLARD, 1974). Assim, temos convertido a ciência em algo desonrado, vil, aviltado, desprezível. A ciência vista como uma forma de ascensão social, de obter riquezas econômicas, de chegar ao poder, de manipulação, de legitimação de verdades ou incertezas, como um parâmetro que indica se uma sociedade é "produtiva" ou não. Um exemplo disso são aqueles pesquisadores que publicam mais e que por isso ganham bolsas, prêmios, qualificações, sendo gratificados pelo sistema e apontados como os "melhores".

Isso leva muitos membros da academia latino-americana a simular que fazem pesquisa e que constroem conhecimento (PARIS, 2012; MACHADO, 2017) talvez numa situação desesperada por pagar as contas do empréstimo do apartamento, o carro zero, as inscrições dos filhos nas escolas privadas, as empregadas domésticas, a viagem dos sonhos a Paris, Londres ou a Nova Iorque. Vivem simulando que desenvolveram um novo projeto, que orientam seis estudantes de pós-graduação, que dão aula em duas universidades, que publicam pelo menos dois ou três artigos por ano, tudo isso para se manter no melhor nível entre os pesquisadores. Não é o caso de citar os nomes daqueles cientistas que incorrem no simulacro, em verdade os temos na ponta dos dedos, prontos para serem teclados. O que não podemos é 
expor alguém pelo fato de simular, pois entendemos que vivemos num sistema que não permite outra coisa a não ser nos tornarmos reféns obscenos do social (BAUDRILLARD, 1996).

\section{O MIGRANTE E O CIENTISTA}

Como já ficou explícito no começo de nosso trabalho, o foco deste texto é de refletir sobre a migração, entendendo esta como um campo cuja abordagem parte sempre de uma perspectiva na qual o migrante é a vítima e por isso precisa de ajuda para ter seus direitos garantidos. Assim, a etnografia e as ferramentas metodológicas se tornam o meio pelo qual se busca "empoderar os migrantes".

Estudiosos de diversas áreas do conhecimento (TOBÓN \& OTELO, 1995; CARNEA \& MCDOWELL, 2000; BELLO, 2001; CASTLES, 2003; ALVARADO \& MASSEY, 2010; PARIS, 2012; TORRENS, 2013) fazem uso da pesquisa qualitativa e da recompilação das falas dos migrantes, supondo que por intermédio desse estudo, estes serão beneficiados pelo reconhecimento social, pelo reconhecimento institucional ou pela oportunidade de externar seus sentimentos. Esse processo aparece como um "desabafo", uma catarse para o migrante, quando, na verdade, ninguém sabe se ele quer expor sua vida, ou se sente a necessidade de ser reconhecido pela sociedade.

Nesses estudos, existe uma mudança que consiste em deixar de ver o migrante como um objeto para ser olhado como pessoa. Essa diferenciação é importante porque significa reconhecer que o migrante está em constante transformação e movimento e, por isso, cada estudo feito sobre ele não só apresentará especificidades e particularidades como também será único e instantâneo. Mas, mesmo diante do exposto, ainda é comum generalizar o fenômeno da migração a partir das localizações geográficas, contexto político, situação econômica etc., quer seja para alimentar os meios de comunicação, quer seja para criar políticas públicas que atendam às necessidades do migrante (como, por exemplo, em BELLO, 2005).

Em outros estudos, quando o migrante se cala, o pressuposto é que isso pode e deve ser analisado. O silêncio, em algumas pesquisas, chega a ser "interpretado" (BATESON, JACKSON, HALEY \& WEAKLAND, 1956) como se fosse uma fala, quando não sabemos se o silêncio, no caso do migrante, significa simplesmente silêncio. Por que temos que decifrá-lo em vez de deixá-lo irradiar sua ilusão? Talvez essa inatividade, esses silêncios tenham valor numa mensagem e, inclusive influenciem os demais atores que estejam em comunicação (GIRBAUMASSANA, 2002). Não obstante, a existência de um axioma meta-comunicacional (que diz 
respeito ao fato de sempre estarmos comunicando), pode não estar enxergando ou captando aqueles momentos em que o migrante não quer expor sua privacidade.

Talvez não haja motivos para os silêncios serem expostos pelos pesquisadores, já que isso pode violentar ainda mais as pessoas que fazem parte do fenômeno social estudado, levando-as a se enfurecer e a se irritar com o cientista, a se vingar deles, falando qualquer coisa, exceto aquilo que pensam, sentem ou experimentaram. Talvez os silêncios sejam o vazio, e como não suportamos este vazio, sempre tentamos preenchê-lo com qualquer coisa que imite ou que seja ilusão da realidade.

Essa histeria referencial e acumulação de informações é tão enigmática e indecifrável quanto o próprio vazio. $\mathrm{O}$ desejo do cientista por saber o que pensa o migrante pode acabar instigando-o e incomodando-o. Assim é que surge a reversibilidade, ou seja, a motivação por parte dos migrantes - objetos de estudos - a fazer de nós - os objetivadores - seus objetos, levando-nos para onde eles querem (BAUDRILLARD, 1996).

A relação entre o migrante e o pesquisador está baseada em hierarquização, pois enquanto o pesquisador chega a se achar poderoso, porque estuda um "marginal", o "marginal" chega a se achar mais importante e superior ao pesquisador porque este último precisa da sua ajuda. Se a pesquisa está baseada, por exemplo, nas histórias de vida de uma família de migrantes, quem deverá ajustar horários, ritmos de vida, gostos específicos na alimentação etc. será o pesquisador e não o pesquisado. Além disso, é o objeto que, num ato desesperado, de incômodo, e de tédio, pode se converter no "pior inimigo da verdade". É justamente nesse ponto que se dá a vingança do objeto sobre quem o objetiva.

Mas em que consiste essa vingança do migrante contra o pesquisador? Como é que se dá essa retorção diante da violência exercida pelos investigadores?

Em uma tentativa de nos aproximar de algum exemplo que possa ser ilustrativo e que permita, até certo ponto, articular uma discussão mais ampla, colocaremos duas de tantas experiências vividas nos últimos seis anos de trabalho com o fenômeno da migração.

\section{As migrantes empresárias}

A primeira experiência vivida foi na Colômbia, aonde fomos conhecer as histórias de vida de algumas mulheres migrantes, deslocadas por conta da guerra entre as Fuerzas Armadas Revolucionarias de Colombia (FARC), o governo, os paramilitares e o narcotráfico (IBARRA, 2014). 
Depois de uma hora e meia de voo da cidade de Bogotá até a cidade de Montería, fomos de táxi a um de seus bairros mais pobres, que se encontrava localizado na periferia da cidade. $\mathrm{O}$ encontro seria ali.

Quando chegamos à reunião, encontramos 16 mulheres todas com idades de 30 a 40 anos, algumas sentadas com seus filhos no colo e outras, em pé. Tudo transcorria como eu "queria": a líder das deslocadas me apresentou às outras, logo elas também se apresentaram e começaram a contar "suas histórias de vida".

Qual foi a nossa surpresa quando, antes de terminar nossa conversação, uma delas pediu a palavra e, falando sobre suas necessidades e carências, escreveu num papel algumas ideias sobre um projeto de uma padaria, sendo assinado por todas. Depois, pediram para converter esse projeto num plano de negócios para ser levado a ONGs e fundações que pudessem thes dar apoio.

Naquele dia, fomos levados não só com o propósito de conhecer as "histórias de vida" das deslocadas, mas também com a finalidade de, sem saber, ajudá-las a montar um projeto econômico. Ou seja, usando suas histórias de vida como ferramenta de persuasão, conseguiram nos afetar e, assim, nos comprometer a fim de servir aos seus propósitos.

A vingança ou retorção do objeto foi tal que hoje em dia é preferível não falar do artigo que versa sobre as histórias de vida daquelas mulheres, porque temos consciência de que tudo aquilo que aconteceu talvez estivesse pré-programado. As experiências contadas pelas deslocadas podem ter sido produto de um fingimento, uma forma de o objeto agradar o pesquisador, de seduzi-lo, e até dominá-lo.

O absurdo, a dissonância, o particular, o lúdico e o engraçado desta experiência comandada pelo objeto acabaram por desmistificar o suposto conhecimento que achávamos que tivéssemos construído por meio de uma metodologia indutiva e de generalidades, em um universo em que a lei é a exceção.

\section{O caso da migrante silenciosa}

Foi durante o primeiro período de 2017 que conheci Ana Maria7. Ela era estudante da Universidade Federal do Estado do Rio de Janeiro e frequentava minhas aulas. Sempre que começo um curso seja qual for, gosto de me apresentar e falar para os estudantes qual é a minha linha de pesquisa, qual minha formação etc.

\footnotetext{
7 Para proteger a privacidade e intimidade do personagem aqui exposto, foi necessário o uso de um nome fictício.
} 
Desde o primeiro dia que falei sobre minhas pesquisas baseadas em histórias de vida dos migrantes, ela me olhou diferente e no final da aula me abordou. Séria e sigilosa, como alguém que guarda um segredo e se aproxima de outro para contá-lo, ela se apresentou a mim, mas foi uma apresentação curta, muito superficial, já que alegava não querer tirar meu tempo ou me atrapalhar. Por isso, propôs me encontrar outro dia, numa hora que fosse acessível para os dois, pois queria me contar algo muito importante.

Os dias e as semanas passaram e Ana Maria não voltou a tocar no assunto, simplesmente assistia esporadicamente à aula, quieta. Algumas vezes participou das discussões, mas isso foi raro. O desenvolvimento acadêmico de Ana Maria foi muito baixo. Quando lancei as primeiras avaliações e viu as notas, voltou a se aproximar para pedir uma reunião em particular, pois ela queria falar comigo sobre seu assunto tão importante. Eu aceitei a reunião e aí foi que ela começou a contar toda a sua "história de vida", inclusive chegou a falar que tinha escrito um poema que queria utilizar em seu trabalho, pois era uma analogia de sua vida marcada pela migração, a vida de uma menina marginal, excluída, sem possibilidades de estudar.

Ana Maria explicou que seu pai tinha terras e que sempre tiveram uma boa vida, mas logo veio uma época difícil e seu pai foi expulso da região onde cultivava, tendo que vender as terras muito abaixo do preço de mercado. Após sair de seu lugar de origem, foram para uma favela, aonde pessoas de diversas universidades se aproximavam para conhecer os motivos dos deslocamentos das famílias que ali se encontravam. Com um rosto que expressava indiferença, Ana Maria falou que aquelas pessoas nunca os ajudaram, que não ganharam nada, e que, aliás, nunca mais as viu por ali.

Pedi para Ana Maria ler o poema que tanto queria usar na estrutura do ensaio. Ela pegou sua mochila e de dentro tirou um trabalho da universidade que tinha apresentado numa outra disciplina no ano 2016. Lá estava o poema. Assim que ela começou a ler, as lágrimas inundaram a sala onde nos encontrávamos.

Fiquei mais de duas horas conversando com ela, tentando encontrar diversas maneiras para ela integrar, na estrutura do seu ensaio final, a história de vida e o poema. Ambos iriam ser utilizados como elementos que sustentanvam a tese que ela queria defender no ensaio: que as instituições brasileiras são estruturas injustas, que incentivam a desigualdade, a ineficiência e a exclusão da mulher.

Naquele dia, fiquei muito comovido, tanto que adiei a data de entrega de seu ensaio, dando-Ihe duas semanas a mais para escrever quatro páginas a serem encaminhadas a mim como sua avaliação final. 
No fim das contas, Ana Maria conseguiu o que queria, ou seja, uma consideração especial, não só pelo fato de ter sofrido, como também porque sabia que eu iria me interessar por sua história de vida como migrante. A leitura que faço é que Ana Maria, pelas experiências que tinha vivido, sabia o quanto é importante para nós, pesquisadores, escutar a história de vida de um migrante. Entendia tão bem isso, que estava ciente de que sua história também era a ferramenta letal que me deixaria desarmado como professor na hora de the exigir o cumprimento dos prazos acordados para entrega do trabalho final.

As retorções aqui descritas são casos particulares. Não pretendemos apresentá-las como evidências irrefutáveis, nem como provas de que o mundo dos migrantes funciona baseando-se na retorção, na vingança para com nós, os vampiros insaciáveis das ciências humanas, os cientistas. Mas, sim, queremos comunicar e compartilhar as reflexões que têm surgido dessas experiências no campo das migrações. Mediante esse exercício reflexivo, nós propomos novos questionamentos que não são habitualmente debatidos, quer seja porque os achamos de menor importância, quer seja porque são perguntas que nos deixam vulneráveis por não terem explicação imediata.

\section{DESAPARIÇÃO DO MIGRANTE OU SIMULAÇÃO?}

É um acaso a tentativa da ciência de trazer consigo a claridade em excesso, a transparência, a luminosidade, as ações de homens e mulheres norteadas pela extrema cautela, a racionalidade e a frieza a responsável pela crise da modernidade? Será que as tentativas de extinguir o instinto para deixar florescer a razão, e de afogar o afeto para promover a moral são os sintomas da decadência? Em que momento se chegou a pensar que a realidade é única e generalizada, quando existe uma infinita acumulação de provas que contradizem aquilo que é supostamente verossímil? É a ciência simulacro e os pesquisadores simuladores? É possível se iludir enquanto se simula? Será que diante de tantas provas que negam a realidade e tantas outras que a afirmam não há outra solução que a ilusão?

O processo de montagem da razão, que simultaneamente tenta ser desconstruído, deu origem à cultura do real que vai se afundando no excesso da realidade, à cultura da informação que vai se afundando no excesso da informação. Vivemos elaborando continuamente sentidos, mesmo sabendo que não existem. É uma simples e complexa ilusão que o mundo vivo nos oferece e nós, seduzidos pelo artifício, pactuamos um acordo no qual o mundo se compromete 
a ser a fonte infinita da ilusão e, a partir dessa ilusão simulamos fabricar o entendimento, a compreensão e a verdade, com a finalidade de dar ordem ao mundo, dar sentido.

Os métodos científicos têm sido os meios mais "geniais" que nos permitem catalogar, categorizar, organizar e inventariar de forma a entender, ler e interpretar as ilusões que o mundo apresenta. O resultado é uma grande montagem cinematográfica de uma razão cuja origem provém da ilusão (BAUDRILLARD, 1995).

As ciências, desde a biologia até a física quântica, todas fazem trabalhos cinematográficos, umas de forma literal enquanto outras, de forma mais implícita. Nas ciências humanas também é comum fazer montagens cinematográficas da verdade usando fotografia, enquadres, iluminação, sequências, roteiros etc.

\section{Migração e cinematografia: o esfumaçamento do migrante?}

Colocaremos, aqui, três exemplos explícitos dessa simulação cinematográfica da verdade.

O primeiro é um documentário mexicano chamado Los que se quedan (2008), sobre o fenômeno da migração internacional para os Estados Unidos. Ele mostra oito histórias de vida de famílias mexicanas que passaram pelo processo de migração internacional para os Estados Unidos. A idealização do American Dream, a desintegração familiar, a trans-culturalidade etc. são algumas das problemáticas abordadas e capturadas pela câmera. A primeira cena do documentário é muito interessante e acontece numa escola localizada nos Altos de Jalisco. A professora que dá aula para mais de uma dúzia de crianças entre quatro e seis anos, thes pergunta: onde estão seus pais? As crianças respondem: nos Estados Unidos. A professora pergunta novamente: que tem nos Estados Unidos? Elas e eles respondem: dinheiro, pulseiras e correntes de ouro. Finalmente, a professora questiona: onde vocês querem morar quando forem maiores de idade? As meninas e os meninos respondem sorridentes: lá nos Estados Unidos.

O segundo é um trabalho jornalístico que se chama Pequeñas voces (2005) e mostra a problemática do conflito armado na Colômbia. É um trabalho feito com a técnica do desenho animado. Mostra o sofrimento das crianças que perderam familiares no conflito armado. Os rostos dos personagens que protagonizam o filme foram feitos com base em referências trazidas pelos desenhos das próprias crianças que sobreviveram ao conflito. As narrativas são 
também contadas por elas e quando suas vozes são entrecortadas pela emoção e pela tristeza os espectadores também são afetados. A violência projetada é impactante.

O terceiro é um trabalho que se chama El lugar más pequeño (2011) e versa sobre os êxodos de pessoas que a guerra civil dos anos de 1970 provocou em El Salvador. O nome da cidade em que foi rodado é Cinquera, que, hoje em dia, é um povoado que se encontra em processo de reconstrução. A diretora Tatiana Huezo, também de Cinquera, explicou em entrevista (PROCESO, 2011) que sua motivação em filmar esse documento digital vinha tanto pelo fato de ter sido habitante da região quanto pela dor que percebia no olhar das pessoas que sobreviveram à guerra civil. Foram nove semanas de filmagem e o resultado é um documentário que, por meio das narrativas de seus cinco personagens, pretende explicar como foi que, escondidos numa cova, sobreviveram ao conflito e como foi, posteriormente, o processo de luto, reinvenção e reconstrução da pequena cidade de El Salvador.

Os três trabalhos cinematográficos são extremamente comoventes, é só assisti-los para ser afetado pelas diferentes estratégias e técnicas da clonagem da realidade. Com isso, não tentamos desqualificar os trabalhos cinematográficos, mas sim, colocar que, o fato de mostrarem as pessoas que vivem o processo da migração em imagem e sons, através da tela e alto-falantes, não significa dizer que essa é a realidade pura. Não se trata tampouco da aproximação científica mais fiel, nunca antes feita sobre o fenômeno da migração, qualquer que seja sua modalidade, podendo, inclusive, significar o extermínio do real em mãos do seu duplo, da imagem, do artifício ou então, da alta definição.

É a representação da realidade mediante o espetáculo, um espetáculo baseado nas relações sociais mediatizadas pelas imagens, uma nova linguagem que movimenta a sociedade moderna. (DEBORD, 1967).

A montagem cinematográfica desenvolvida pelas ciências humanas com a finalidade de "captar a realidade" do fenômeno das migrações, onde a imagem, o som e a iluminação configuram um novo olhar sobre o fenômeno, é uma estratégia que se encaixa à perfeição num mundo em que não basta procurar novas especificidades, elementos microscópicos do fenômeno das migrações, mas também se exige que isso seja feito em alta definição. Isso significa que as imagens e o som podem ser projetados numa velocidade instantânea através de uma tela, quer seja a de um celular, a de um tablete, ou até mesmo a de um computador.

Para cativar e seduzir alguém que faz parte da "civilização" do espetáculo, não é suficiente mostrar as gravações das experiências dos migrantes, não basta transcrever as narrativas, pois isso poderia torna-se entediante. Para garantir entretenimento mediante um 
trabalho "espetacular" talvez seja preciso mostrar o migrante ao vivo. Captar explicitamente o sofrimento dos migrantes e seus "carrascos", os autores do ato violento, é garantir o espetáculo ${ }^{8}$.

As ciências humanas não fugiram da lógica do espetáculo, transformaram "as problemáticas de pesquisa do mundo real" em imagens que, por sua vez, chegaram a se converter em personagens "reais". As montagens cinematográficas são, justamente, uma das técnicas mais eficazes para isso, já que recorrem à visão, o sentido mais privilegiado do homem no mundo moderno. Assim, mediante as imagens, o som etc. se pretende prender e mostrar, numa perspectiva abstrata, as especificidades da sociedade atual.

O mundo moderno exige espetáculo e vai além do ouvir e do olhar, pois para ele se reconstituir, precisa justamente da degradação da verdade, da relativização do mundo, da especulação da vida. A necessidade do homem de fazer constante correção sobre seus próprios fazeres, seu desejo de organizar o mundo e reconsiderá-lo em suas formas é o que leva a ciência a querer saber mais sobre o objeto de estudo e, em nosso caso específico, a migração.

Por meio da construção de provas palpáveis, provas replicadas, partes desfiadas e analisadas, num processo parecido com aquele de retirar camada por camada a pele de uma cebola, a pergunta que nos vem à mente é: o que resta depois de tirar uma a uma as camadas de uma cebola? A resposta é simples: nada parecido com uma cebola. O que resta são suas camadas espalhadas no tabuleiro. Estamos acostumados a visualizar esse processo exaustivo de análise, denominado hiper-realidade de pegadas ou provas (BAUDRILLARD, 1995), como um processo construtivo, quando na verdade é um processo de exploração da ciência sobre o objeto de estudo, que normalmente acaba por exterminar o objeto real, tal como aconteceria com a retirada das camadas da cebola.

A histeria referencial ou o transtorno compulsivo obsessivo da acumulação de informações e provas é, talvez, um dos processos que pode levar à desaparição das pegadas que mostrem que algum dia existimos, não só na condição de seres curiosos, como também na de seres afetivos.

\footnotetext{
${ }^{8}$ A divisão do mundo em dois discursos: o "nós" versus o "eles", é um elemento que gera espetáculo no mundo mediatizado. É a famosa luta do bem contra o mal, quer dizer, é a base do nosso pensamento ocidental. Toda ação que esteja fora do socialmente aceito vai ser rejeitada, individualmente ou coletivamente, pois não o fazer significa a possibilidade de entorpecer ou atrapalhar o caminho para o "progresso". Por isso é muito importante, para os trabalhos cinematográficos sobre problemáticas sociais, construir uma luta explícita ou implícita entre o "bem" e o "mal", entre "progresso" e "retrocesso", pois essa polarização pode ajudar os cineastas a alcançar seu objetivo primário: ganhar viewers ou pessoas que estejam interessadas em assistir aquilo que foi "captado" pela câmara.
} 
Será então que os estudos científicos e sua violência intrínseca estão fazendo desaparecer o "migrante real"? Talvez o migrante, ao sentir-se agredido e violentado, optou pela retorção, pela vingança, e mesmo antes de ser descascado, desfiado e desmembrado pelo cientista, resolveu simular sua desaparição? Será que a linha entre o horizonte da "verdade pura" e a simulação acabam por diluir-se no mundo da virtualidade em alta definição, onde a técnica se sobrepõe ao migrante, ao real e, inclusive, à imagem e à representação?

\section{CONSIDERAÇÕES FINAIS}

Quando estudamos o fenômeno da migração, o que captura nossa visão muitas vezes é aquilo que se encontra ao alcance do nosso olhar, aquilo que observamos. Por exemplo, a vulnerabilidade sob a qual vivem os migrantes, quer seja nos campos de refugiados na Itália, na Alemanha ou na França, quer seja nas comunidades latinas localizadas nos Estados Unidos onde os migrantes vivem ocultando-se da Inmigration Police para não serem deportados, ou mesmo nos cinturões de miséria onde, improvisadamente, as famílias expulsas das zonas rurais no México (territórios convertidos hoje em campos de luta em que se enfrentam cartéis das drogas, crime organizado e instituições de segurança pública) se "refugiam da violência". Esses exemplos de precariedade da vida do migrante pululam nos estudos acadêmicos, nos meios de comunicação e, inclusive, são de domínio popular, e sem sombra de dúvida são fatos que versam sobre uma crise que deve ser atendida urgentemente.

Não obstante, o que interessa neste trabalho transdisciplinar é mostrar que reler os discursos dominantes sobre o fenômeno das migrações é um exercício metodológico, é uma rota que pode abrir um caminho à reflexão, numa tentativa de conhecer como conhecemos, quer dizer, de nos voltarmos sobre nós mesmos no desejo infinito de tentar descobrir justamente aquilo que pode estar fugindo de nosso olhar. E podemos nos arriscar ainda mais, pois reler esses discursos é um exercício que pode "nos esvaziar" e com isso fazer surgir novas questões: Como é constituído o objeto, o migrante? O que está sendo excluído? O que esses discursos dominantes da ciência estão produzindo em termos sociais, culturais, políticos e econômicos? Falar do migrante em uma pesquisa é lhe dar algum tipo de reconhecimento?

Foram essas as perguntas que nos levaram às questões levantadas neste artigo, e que nos conduziram a uma nova abordagem do problema e, mais especificamente, às retorções dos migrantes e à possível relação entre elas e o ato violento da pesquisa. Essa é uma das tantas outras especificidades ou fragmentos da realidade constituinte do migrante que nós, como 
cientistas, às vezes passamos por alto. Porém, o que este trabalho descreve é só a ponta de um iceberg que se encontra submerso em um vasto oceano de possibilidades, combinações, sem sentidos e movimentos infinitos, que envolvem o fenômeno social da migração.

Finalmente, queremos apontar que, durante o processo de reflexão, alguns outros elementos constituintes do migrante que nós não tínhamos considerado saltaram à vista, nos deixando instigados. Um desses elementos é o da construção da memória social. Além disso, diversos questionamentos também surgiram em forma de desafios futuros sobre a migração: Como estudar o processo de construção de memória no migrante que apresenta a retorção? Que papel desempenha a violência no processo de configuração de memória? Qual corrente de análise pode nos oferecer uma abordagem menos violenta para com as pessoas que fazem parte daquele fenômeno social que estamos estudando? São esses os elementos e questionamentos que pretendemos abordar em nossos próximos estudos.

\section{REFERÊNCIAS}

ALVARADO, S.; MASSEY, D. Em búsqueda de la paz: ajuste estructural, violencia y migración internacional en México y Centroamérica, 1979-2002. In: DONATO, K. M. Salvando fronteras. Migración internacional en América Latina y el Caribe. México, Vanderbilt University, Mexican Migration Project y Miguel Ángel Porrúa, 2010.

BATESON, G.; JACKSON, D.; HALEY, J.; \& WEAKLAND, J. Toward a theory of schizophrenia. Behavioral Science, 1, (14), 1956.

BAUDRILLARD, J. La sociedad de consumo. México: Siglo XXI, 1974.

El crimen perfecto. Barcelona: Anagrama, 1996.

As estratégias fatais. Rio de Janeiro. Rocco, 1996.

BELLO, M. N. Desplazamiento forzado y reconstrucción de identidades. Colombia: Instituto Colombiano para el Fomento de la Educación Superior, 2001.

El desplazamiento em Colombia, regiones, ciudades y políticas públicas. Medellín: REDIF ACNUR, 2005.

BENJAMIN, W. Sobre el concepto de la historia. Chile: Centro de Estudios Miguel Enriquez, 2008.

BLUMER, H. Symbolic interactionism: perspective and method. U.S.A: University of California, 1969. Acessado em 25 de maio de 2014. Disponível em: http://books.google.com.mx/books?id=HVuognZFofoC\&printsec=frontcover\&hl=es\#v=onepage $\& q \& f=f a l s e$

CARNEA, M.; MCDOWELL, C. Risk and reconstrucction: Experiences of - resettlers and refugees, U.S.A: World Bank, 2000. 
CASTLES, S. La política internacional de la migración forzada. Migración y desarrollo, 1. 2003. Acessado em 03 de março de 2013. Disponível em: www.migraciónydesarrollo.org

CHAMBERS, I. Migración, Cultura, Identidad. Argentina: Amorrortu, 1994.

DEBORD. G. La sociedad del espectáculo. España: Pre-Textos, 1999.

DURIN, S. Los que la guerra desplazó: familias del noreste de México em el exilio. Desacatos. 38, 2012.

DURSTON, J.; MIRANDA, F. Experiencias y metodología de la investigación participativa. Chile: CEPAL, 2002.

FARIAS, F. R. et al. Quatro questionamentos da violência. Rio de Janeiro, Contra Capa, 2014.

FREUD, S. Por que a guerra? (1932). Rio de Janeiro: Imago, 1976.

FOUCAULT, M. As palavras e as coisas. São Paulo: Martins Fontes, 2000.

GIRBAU-MASSANA, D. Psicologia de la comunicación. Barcelona: Ariel, 2002.

HUSSERL, E. Crisis de las ciências europeas y la fenomenologia transcendental. México: Folios, 1984.

IBARRA, C. E. El desplazamiento forzado y la identidade de la mujer, El caso de um pueblo em Colombia. Revista Arenas, 37, 2014.

KAUFFER, E. Movimientos migratórios forzosos em la frontera sur: una visión comparativa de los refugiados guatemaltecos em el sureste de mexicano. Identidades, migraciones y género em la frontera sur de México. México: El Colegio de la Frontera Sur, 2002.

MACHADO, R. Michel Foucault: Pensador e ativista. Rio de Janeiro: EdUFRJ, 2017.

MERLEAU-PONTY, M. Fenomenologia de la percepción. México: Planeta-De Agostini, 1993.

PARÍS, M. D. De la observación participativa a la investigación militante em las ciências sociales: el estudio de comunidades indígenas migrantes. Métodos cualitativos y su aplicación empírica: por los caminos de la investigación sobre la migración internacional. México: UNAM, 2012.

PROCESO. El lugar más pequeño, un documental estrujante. 7 de fevereiro de 2011. Acessado em 05 de agosto de 2017. Disponívelem:http://www.proceso.com.mx/262334/262334-el-lugarmas-pequeno-un-documental-estrujante

STENGERS, I. A invenção das ciências modernas. São Paulo: Ed. 34, 2002.

TOBÓN, G.; OTERO, Y. Mujeres y desplazamiento, una realidad en la ciudad de Montería. Colombia: Corporación María Cano, 1995.

THOMAS, W. I.; ZNANIECKY, F. The Polish peasant. New York: Dover Pub, 1918. 
TORRENS, Ó. El desplazamiento interno forzado en México: um acercamiento para su reflexión y análisis. México: CIESAS y El Colegio de la Frontera, 2013.

TOURAINE, A. Crítica a la modernidade. México: Fondo de Cultura Económica, 1992.

Videos

HUEZO, T. El lugar más pequeno. Centro de Capacitación Cinematográfica, FOPROCINE. México: 2011, $108 \mathrm{~min}$, Som, Cor, Formato: $35 \mathrm{~mm}$.

CARRILLO, J.; ANDRADE, O. Pequeñas vocês. Jaguar Taller Digital - La máquina producciones, Colômbia: 2010, 76 min. Som, Cor, Formato: 3D.

RULFO, J. C.; HAGERMAN, C. Los que se quedan. La media Luna, La sombra del guayabo, SONY México, Beca Gucci-AMBULANTE, Fundación Bancomer, Vale Euro RSCG, Corazón Films, México, 2008, $99 \mathrm{~min}$. Som, Cor, Formato: 35mm. Acessado em 25 de julho de 2017. Disponivel em: https://www.youtube.com/watch?v=M1bFrO-vk-Y

Trabalho enviado em 24 de setembro de 2017.

Aceito em 13 de fevereiro de 2018. 